\title{
Potential Effectiveness of Minidose Aspirin Combined with Dilazep in Anti-Platelet Therapy
}

\author{
Kojiro YASUNAGA*1 Kanshi MASE*1 Katsuaki NAKAJIMA*2 \\ Susumu YAMAMOTO*2 and Masahiko NAGAKURA*2
}

\author{
(Received on October 29, 1987) (Express) \\ *1 The First Department of Internal Medicine, Kansai Medical University, Osaka, Japan \\ *2 Tokyo Research Laboratories, Kowa Co., Ltd., 2-17-43 Noguchi-cho, Higashimurayama, \\ Tokyo 189, Japan
}

The anti-platelet aggregating action of minidose aspirin and its combined effect with dilazep were examined in healthy male volunteers. A quantitative and dose-dependent decrease in platelet aggregability was observed on a single oral administration of $30 \mathrm{mg}$, $100 \mathrm{mg}$ and $300 \mathrm{mg}$ of aspirin and also on the repeated oral administration of $10 \mathrm{mg}$ and $30 \mathrm{mg}$ three times a day for 5 days. Administration of $100 \mathrm{mg}$ of dilazep in combination with $30 \mathrm{mg}$ or $100 \mathrm{mg}$ of aspirin produced an anti-platelet effect equivalent to a 3 -fold dose of aspirin alone. In the repeated administration test, the t. i.d. administration of aspirin $10 \mathrm{mg}+$ dilazep $100 \mathrm{mg}$ was confirmed to be close to the ideal in the balance between anti-platelet action and the reduced production of $\mathrm{PGI}_{2}$.

Key words : anti-platelet therapy, minidose aspirin, dilazep, platelet aggregability, $\mathrm{PGI}_{2}$

\section{Introduction}

In treatment or prophylaxis of thrombotic diseases the usefulness of aspirin as an anti-platelet agent has been recognized. ${ }^{1-3)}$ However, there are associated problems such as the development of gastrointestinal disturbances and inhibition of $\mathrm{PGI}_{2}$ production in the vascular wall.4,5) Accordingly, a selective minidose of aspirin seems significant for the anti-platelet therapy with this drug. ${ }^{6-8)}$

On the other hand, it is known that dilazep dihydrochloride (Comelian ${ }^{\circledR}, 1,4$-bis- $[3-(3,4,5$ trimethoxybenzoyloxy) propyl] perhydro-1, 4-diazepine dihydrochloride monohydrate), a coronary vasodilator $^{9)}$ and cerebral vasodilator, ${ }^{10)}$ acts not only to increase peripheral flow but also to potentiate the abilities of erythrocyte oxygen dissociation and blood fibrinolysis. ${ }^{11-13)}$ Moreover, its anti-platelet action, based on its membrane stabilizing

*1 関西医科大学第一内科

*2 興和株式会社東京研究所 于189 東村山市野口町 2-17-43 action and $\mathrm{Ca}^{2+}$ antagonism, ${ }^{14 \sim 16)}$ suggests that this drug may be applicable in the combination with aspirin for treatment of thrombotic disease.

From this viewpoint we previously performed ex vivo experiments using experimental animals, and the results showed that the combined administration of aspirin and dilazep potentiated an anti-platelet action, without influencing $\mathrm{PGI}_{2}$ production in the vascular wall. ${ }^{17)}$ Therefore, we conducted a crossover study using healthy male volunteers and confirmed the usefulness of the combination of both drugs from the viewpoint of clinical pharmacology.

\section{Materials and Methods}

\section{Drugs}

Aspirin (the standards of the Japanese Pharmacopoea) was purchased from Eisai Co. It was diluted 20-fold with lactose to prepare a powder for ingestion. Dilazep was presented from Kowa Co. (Comelian ${ }^{\circledR} 50 \mathrm{mg}$ Tablets).

\section{Single ad ministration test}

A total of 12 healthy male volunteers (age, 27.8 
Tab. 1 Schedule for single-dose crossover study of combined oral administration of aspirin and dilazep in 12 healthy male volunteers

\begin{tabular}{|c|c|c|c|c|c|c|c|}
\hline \multirow{2}{*}{ Group } & \multirow{2}{*}{ Volunteer } & \multirow{2}{*}{$\begin{array}{c}\text { Age } \\
(\mathrm{yr})\end{array}$} & \multirow{2}{*}{$\begin{array}{c}\text { Height } \\
\text { (cm) }\end{array}$} & \multirow{2}{*}{$\underset{(\mathrm{kg})}{\mathrm{B} . \mathrm{W}}$} & \multicolumn{3}{|c|}{ Dosage (mg) } \\
\hline & & & & & Exp. 1 & Exp. 2 & Exp. 3 \\
\hline \multirow{2}{*}{ I } & A & 32 & 161 & 62 & A $30+D 100$ & A 30 & A 300 \\
\hline & B & 29 & 165 & 64 & A $30+$ D 100 & A 30 & A 300 \\
\hline \multirow{2}{*}{ II } & $\mathrm{C}$ & 28 & 167 & 70 & $\mathrm{~A} 100+\mathrm{D} 100$ & $\mathrm{~A} 30+\mathrm{D} 100$ & A 30 \\
\hline & $\mathrm{D}$ & 26 & 174 & 76 & $\mathrm{~A} 100+\mathrm{D} 100$ & $\mathrm{~A} 30+\mathrm{D} 100$ & A 30 \\
\hline \multirow{2}{*}{ III. } & $\mathrm{E}$ & 27 & 169 & 58 & A 30 & A 100 & A $30+$ D 100 \\
\hline & $\mathrm{F}$ & 26 & 172 & 66 & A 30 & A 100 & A $30+D 100$ \\
\hline \multirow{3}{*}{ IV } & G & 25 & 170 & 68 & A 100 & A 300 & $\mathrm{~A} 100+\mathrm{D} 100$ \\
\hline & $\mathrm{H}$ & 27 & 178 & 80 & A 100 & A 300 & $\mathrm{~A} 100+\mathrm{D} 100$ \\
\hline & I & 28 & 170 & 74 & $\mathrm{~A} 300$ & $\ldots \ldots$ & A 100 \\
\hline \multirow{3}{*}{ V } & $\mathrm{J}$ & 30 & 172 & 72 & A 300 & $\mathrm{~A} 100+\mathrm{D} 100$ & A 100 \\
\hline & K & 28 & 178 & 72 & $\ldots \ldots$ & $\ldots \ldots$ & A 30 \\
\hline & $\mathrm{L}$ & 28 & 178 & 72 & $\cdots \cdots$ & ...... & $\mathrm{A} 100+\mathrm{D} 100$ \\
\hline mean $\pm \mathrm{SD}$ & & $27.8 \pm 1.9$ & $171.2 \pm 5.4$ & $69.5 \pm 6.2$ & & & \\
\hline
\end{tabular}

After each experiment, all volunteers had a washing-out period of two weeks during which the antiplatelet effect of high-dose aspirin disappeared completely. A; aspirin, D; dilazep

$\pm 1.9 \mathrm{yr})$ were divided into 5 groups which participated in three crossover tests following the schedule in Tab. 1. The drugs were taken at $9 \mathrm{a}$. m. during fasting. Blood was collected from the elbow vein before administration, and $0.5,1,3,6$, and $24 \mathrm{hr}$ after administration using a plastic syringe (containing $1 / 10$ volume of $3.8 \%$ sodium citrate solution). Meals were taken twice a day, i.e., immediately after blood sampling at $1 \mathrm{p} . \mathrm{m}$. and at 6 p. m. Platelet aggregability was determined by the method of Born. ${ }^{18)}$ Collected blood was centrifugated at $200 \times g$ for $7 \mathrm{~min}$ to prepare platelet rich plasma (PRP) then the residue was centrifugated at $1,500 \times g$ for $10 \mathrm{~min}$ to give platelet poor plasma (PPP). A glass tube containing $250 \mu \mathrm{l}$ of PRP was set up in an aggregometer (NKK, Hematracer 1), and after preincubation for $1 \mathrm{~min}$, $10 \mu \mathrm{l}$ of collagen suspension (Horm Co.) was added to give final levels of $0.5,1,2$, and $4 \mu \mathrm{g} / \mathrm{ml} \mathrm{PRP}$ and aggregation curves were recorded. Plasma salicylic acid levels and blood dilazep levels were determined respectively by high-performance liquid chromatography and GC/MS (selective ion monitoring).

\section{Repeated t.i.d. administration test}

A total of 16 healthy male volunteers (age, $22.4 \pm 1.5 \mathrm{yr}$ ) were divided into 5 groups which participated in two crossover tests following the schedule in Tab. 2. The drugs were administered in designed doses three times a day (9 a.m., noon,
5 p. m.) repeatedly for 5 days. Meals were taken $30 \mathrm{~min}$ after each drug intake. Blood was collected under the same conditions as in the single-administration test, three times a day (immediately before drug intake at 9 a.m., noon, and 3 p.m.) on the first 3 days after the start of administration, and once a day (immediately before drug intake at 9 a. m.) on day 4 and day 5 . After completion of the repeated administration for 5 days, a period of nonadministration began during which blood was collected at $9 \mathrm{a} . \mathrm{m}$. on day 3 and day 7 . The collected blood was treated similarly to that in the singleadministration test and used for the determination of platelet aggregability. In addition, the blood collected 6,24 and $72 \mathrm{hr}$ after the start of administration and at $9 \mathrm{a} . \mathrm{m}$. on day 7 during the period of non-administration was used for the assay of plasma $\mathrm{TXB}_{2}$ and 6-keto- $\mathrm{PGF}_{1 \alpha}$ levels which were estimated by radioimmunoassay method (RIA kit. New England Nuclear).

\section{Analysis of platelet aggregability}

Platelet aggregability was calculated as reported previously. ${ }^{17)}$ The maximal aggregation velocity (maximal decrease rate of optical density: \%/min) was calculated from aggregation curves at each level of added collagen as shown in Fig. 1 (A), and the dose-response curve was prepared as shown in Fig. 1 (B). Similar dose-response curves were prepared from the aggregation curves obtained after drug administration. In this case, the stronger the 
Tab. 2 Schedule for repeated-dose crossover study of combined oral administration of aspirin and dilazep in 16 healthy male volunteers

\begin{tabular}{|c|c|c|c|c|c|c|}
\hline \multirow{2}{*}{ Group } & \multirow{2}{*}{ Volunteer } & \multirow{2}{*}{ Age (yr) } & \multirow{2}{*}{ Height $(\mathrm{cm})$} & \multirow{2}{*}{ B. W. (kg) } & \multicolumn{2}{|c|}{ Dosage (mg, 3 times a day for 5 days) } \\
\hline & & & & & Exp. 1 & Exp. 2 \\
\hline \multirow{3}{*}{ I } & a & 25 & 170 & 72 & $\mathrm{~A} 10+\mathrm{D} 100$ & A 10 \\
\hline & b & 22 & 180 & 62.5 & $\mathrm{~A} 10+\mathrm{D} 100$ & A 10 \\
\hline & $\mathrm{c}$ & 22 & 170 & 55.5 & $\mathrm{~A} 10+\mathrm{D} 100$ & A 10 \\
\hline \multirow{3}{*}{ II } & d & 23 & 175 & 78 & $\mathrm{~A} 30+\mathrm{D} 100$ & A 30 \\
\hline & $\mathrm{e}$ & 24 & 175 & 58 & $\mathrm{~A} 30+\mathrm{D} 100$. & D 100 \\
\hline & $\mathrm{f}$ & 26 & 160 & 53 & $\mathrm{~A} 30+\mathrm{D} 100$ & D 100 \\
\hline \multirow{3}{*}{ III } & $\mathrm{g}$ & 22 & 170 & 66 & A 10 & $\mathrm{~A} 10+\mathrm{D} 100$ \\
\hline & $\mathrm{h}$ & 23 & 173 & 63 & A 10 & $\mathrm{~A} 10+\mathrm{D} 100$ \\
\hline & $\mathrm{i}$ & 21 & 171 & 57.5 & A 10 & $\mathrm{~A} 10+\mathrm{D} 100$ \\
\hline \multirow{3}{*}{ IV } & $\mathrm{j}$ & 22 & 171 & 73 & $\mathrm{~A} 30$ & $\mathrm{~A} 30+\mathrm{D} 100$ \\
\hline & $\mathrm{k}$ & 22 & 176 & 60 & A 30 & $\mathrm{~A} 30+\mathrm{D} 100$ \\
\hline & 1 & 21 & 175 & 56 & A30 & D100 \\
\hline \multirow{4}{*}{ V } & $\mathrm{m}$ & 21 & 173 & 63 & D100 & A 30 \\
\hline & $\mathrm{n}$ & 20 & 172 & 58 & D100 & $\mathrm{A} 30+\mathrm{D} 100$ \\
\hline & o & 21 & 179 & 71 & $\ldots \ldots$ & D 100 \\
\hline & $\mathrm{p}$ & 22 & 187 & 76 & $\ldots \ldots$ & A 30 \\
\hline \multicolumn{2}{|c|}{ mean $\pm \mathrm{SD}$} & $22.4 \pm 1.5$ & 173. $7 \pm 5.6$ & $64.1 \pm 7.7$ & & \\
\hline
\end{tabular}

A four-week interval was left between experiment 1 and experiment 2 to completely wash out the antiplatelet effect of aspirin. A; aspirin, D; dilazep.
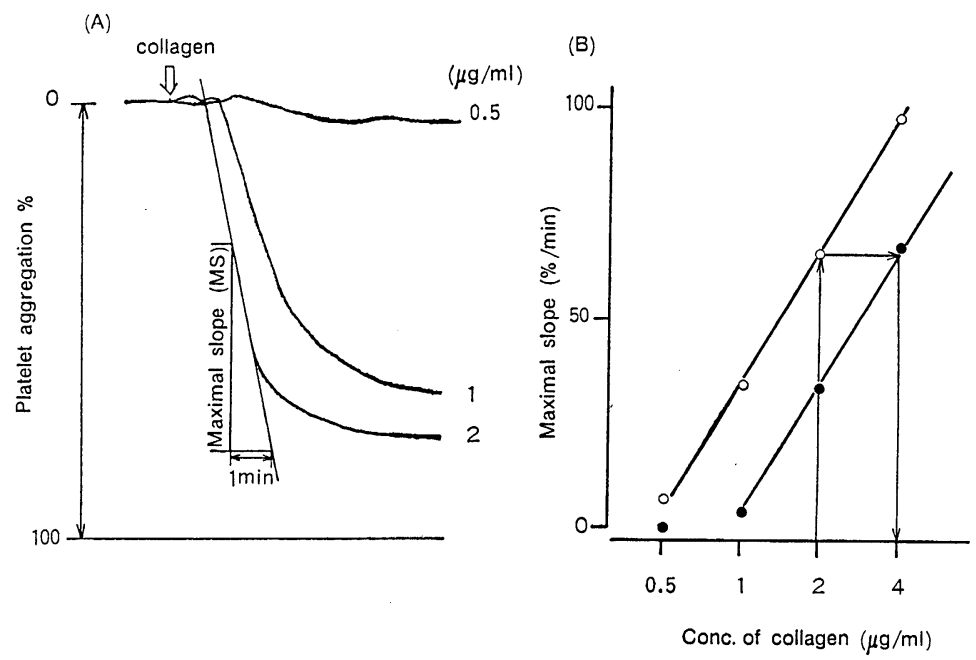

Fig. 1 Analytical method for the estimation of collagen-induced platelet aggregability. (A) : Calculation of maximal slope $(\% / \mathrm{min})$ of collagen-induced platelet aggregation curves. (B): Calculation of platelet aggregability (\%) using the curve relating maximal slope of platelet aggregation and concentration of collagen added. $\mathrm{O}-\mathrm{O}$, before medication; $\bullet-\bullet$, after medication.

anti-platelet action of the drug is, the longer will be distance between the dose-response curves before and after administration. Figure 1 (B) implies that a 2 -fold dose of collagen is needed for the med- icated blood platelets to give the same magnitude of platelet aggregation as the non-medicated blood platelets where the medicated platelet aggregability was expressed as having decreased to $1 / 2$ or $50 \%$. 


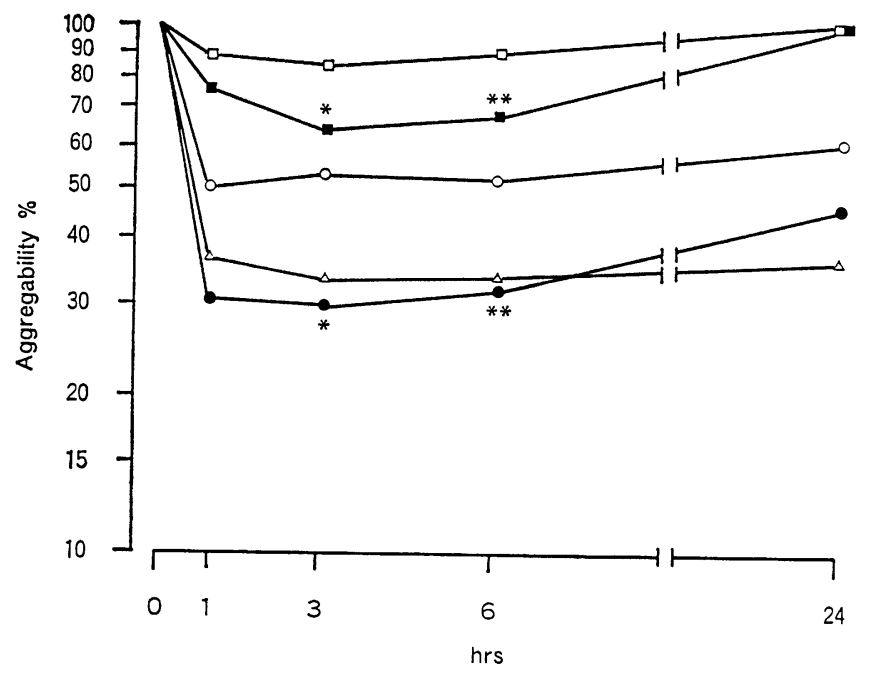

Fig. 2 Time course of platelet aggregability induced by collagen after single oral administration of aspirin and dilazep in healthy male volunteers. Each value represents the mean of 6 volunteers $\square-\square, 30 \mathrm{mg}$ of aspirin; O-O, $100 \mathrm{mg}$ of aspirin; $\Delta-\Delta, 300 \mathrm{mg}$ of aspirin; $\mathbf{m}, 30 \mathrm{mg}$ of aspirin and $100 \mathrm{mg}$ of dilazep; $\bullet-\bullet, 100 \mathrm{mg}$ of aspirin and $100 \mathrm{mg}$ of dilazep. Significantly different from the corresponding aggregability with aspirin alone $(*, \mathrm{P}<0.05 ; * *, \mathrm{P}<0.01)$.

\section{Results}

\section{Single administration test}

Changes in platelet aggregability of the various drug administration groups are shown in Fig. 2. In the aspirin $30 \mathrm{mg}$ group, aggregability decreased slightly to $84.3 \pm 5.6 \%$ after $3 \mathrm{hr}$ and returned to the initial value $24 \mathrm{hr}$ after drug administration. In the aspirin $100 \mathrm{mg}$ group, platelet aggregability decreased to $49.5 \pm 8.7 \% 1 \mathrm{hr}$, to about $50 \% 3$ and $6 \mathrm{hr}$, and remained at $59.2 \pm 4.2 \% 24 \mathrm{hr}$. In the aspirin $300 \mathrm{mg}$ group, it decreased to $36.0 \pm 5.3 \%$ $1 \mathrm{hr}$ and remained to almost the same extent up to $24 \mathrm{hr}$. In the combination group of aspirin $30 \mathrm{mg}$ and dilazep $100 \mathrm{mg}$, platelet aggregability showed significant decreases to $75.0 \pm 9.4,63.3 \pm 3.4$, and $66.7 \pm 4.8 \%$ respectively 1,3 and $6 \mathrm{hr}$ compared with the group given aspirin $30 \mathrm{mg}$ alone, but it returned to $97.2 \pm 3.0 \%$ of the initial value $24 \mathrm{hr}$ after drug administration. In the combination group of aspirin $100 \mathrm{mg}$ and dilazep $100 \mathrm{mg}$, it showed significantly lower values of $30.5 \pm 3.9$, $29.7 \pm 3.2$, and $32.0 \pm 3.6 \%$ respectively 1,3 , and $6 \mathrm{hr}$ in comparison with the group given aspirin $100 \mathrm{mg}$ alone. In addition, the inhibitory action persisted at $44.7 \pm 6.3 \% 24 \mathrm{hr}$ later. Changes in plasma salicylic acid levels and blood dilazep levels are shown in Fig. 3. Salicylic acid levels peaked $30 \mathrm{~min}$ after administration, the peak heights depending on the dose of aspirin. No difference in plasma salicylic acid levels was observed between the aspirin-alone group and the dilazep combination group (Fig. 3 A). Also, plasma dilazep levels showed no difference when dilazep was given in combination with $30 \mathrm{mg}$ or $100 \mathrm{mg}$ of aspirin, in both cases reaching the maximal blood level of 90 $\mathrm{ng} / \mathrm{ml}$ blood (Fig. $3 \mathrm{~B}$ ).

\section{Repeated t.i.d. administration test}

Changes in platelet aggregability before and during drug administration (5 days), and 7 days after cessation are shown in Fig. 4. In the aspirin 10 $\mathrm{mg}$ (daily $30 \mathrm{mg}$ ) administration group, the inhibitory action developed from day 3 of administration, and aggregability showed $39.4 \pm 5.7 \%$ on day 4 and $36.6 \pm 4.6 \%$ on day 5 . After cessation, aggregability began to recover and returned to $94.8 \pm$ $10.2 \%$ of the initial value on day 7 . In the aspirin $30 \mathrm{mg}$ (daily $90 \mathrm{mg}$ ) administration group, the onset of an obvious inhibitory action was observed on day 2 after the start of administration, and aggregability fell to about $20 \%$ during the adminis- 
(A)

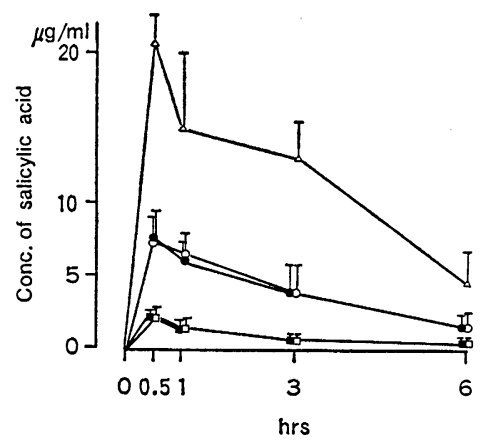

(B)

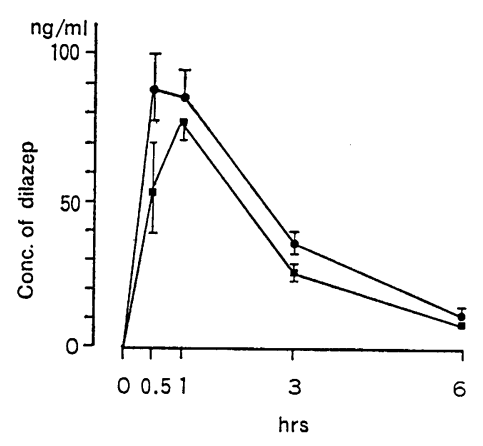

Fig. 3 Plasma concentration of salicylic acid (A) and concentration of dilazep (B) after single oral administration of aspirin and dilazep. (A): $\square-\square, 30 \mathrm{mg}$ of aspirin $(\mathrm{n}=$ 5); $\mathbf{m}-\mathbf{m}, 30 \mathrm{mg}$ of aspirin and $100 \mathrm{mg}$ of dilazep $(\mathrm{n}=4) ; 0-0,100 \mathrm{mg}$ of aspirin $(\mathrm{n}=4) ; \bullet-\bullet, 100 \mathrm{mg}$ of aspirin and $100 \mathrm{mg}$ of dilazep $(n=5) ; \Delta-\Delta, 300 \mathrm{mg}$ of aspirin $(\mathrm{n}=4) \quad(B): \mathbf{m}-\mathbf{m}, 30 \mathrm{mg}$ of aspirin and $100 \mathrm{mg}$ of dilazep $(\mathrm{n}=6)$; $\bullet-\bullet, 100 \mathrm{mg}$ of aspirin and $100 \mathrm{mg}$ of dilazep $(\mathrm{n}=7)$. Each value represents the mean $\pm \mathrm{SE}$.

tration period. On day 3 after cessation it recovered to $66.5 \pm 9.5 \%$, but even on day 7 it remained depressed at $72.3 \pm 4.8 \%$. In the dilazep $100 \mathrm{mg}$ (daily $300 \mathrm{mg}$ ) administration group, a slight inhibitory action appeared immediately after the start of administration, and, although aggregability returned to the initial value $24 \mathrm{hr}$ later on the first 3 days, persistent changes in the inhibitory action were observed thereafter. After cessation it gradually recovered and returned to $94.6 \pm 4.8 \%$ of the initial value on day 7 . In the combined administration group of aspirin $10 \mathrm{mg}$ and dilazep $100 \mathrm{mg}$, platelet aggregability fell to about $60 \%$ immedi- ately after the start of administration (3 or $6 \mathrm{hr}$ later), a significant decrease compared with the aspirin $10 \mathrm{mg}$ alone group. In the combined administration group of aspirin $30 \mathrm{mg}$ and dilazep 100 $\mathrm{mg}$, platelet aggregability decreased to about $10 \%$ from day 2 after the start of administration, a significant decrease in comparison with the aspirin 30 $\mathrm{mg}$ alone group. Platelet function recovered to about $80 \%$ on day 7 after cessation. Plasma levels of $\mathrm{TXB}_{2}$ and 6-keto-PGF $\mathrm{PG}_{1 \alpha}$ before, during drug administration, and on day 7 after cessation are shown in Table 3. The pretreatment values of $\mathrm{TXB}_{2}$ varied in each group at the range of $179-235$ $\mathrm{pg} / \mathrm{ml}$. The single administration groups of aspirin $10 \mathrm{mg}$, aspirin $30 \mathrm{mg}$, and dilazep $100 \mathrm{mg}$ showed a slight decrease in $\mathrm{TXB}_{2} 6 \mathrm{hr}$ after the start of administration. $\mathrm{TXB}_{2}$ values remained slightly low during the administration period but returned almost to the initial values on day 7 after cessation. In the combined administration groups of aspirin and dilazep, $\mathrm{TXB}_{2}$ values decreased to a similar extent and no significant difference was found from the non-combined groups. The initial levels of 6-keto-PGF ${ }_{1 \alpha}$ also varied in each group at the range of $30.7-40.7 \mathrm{pg} / \mathrm{ml}$. These values showed a slight ups and downs during the administration period in all of the treatment groups, but no significant difference was observed from the initial values.

\section{Discussion}

The clinical dose of aspirin as an antipyretic analgesic is generally $600-1,500 \mathrm{mg}$ (t. i. d)/day. These doses have been adopted when aspirin was used as an anti-thrombotic agent. A dilemma arose, however, when it was found, by elucidation of the anti-platelet mechanism of aspirin, that aspirin inhibited the production of $\mathrm{PGI}_{2}$ in the vascular wall. ${ }^{4-6)}$ Since then, the low-dose usage of aspirin and the utility of aspirin in combination with other drugs have been discussed, ${ }^{3,6-8,19)}$ but few clinicopharmacological analyses of the anti-platelet action of aspirin have been reported. One reason may be problems in the determination and the analysis of platelet aggregability. Previously, ${ }^{17)}$ we administered aspirin and dilazep in combination to experimental animals and presented a pharmacological analysis of their anti-platelet actions. In the present clinical trial using human volunteers, a similar method for quantitative analysis of platelet aggreg- 


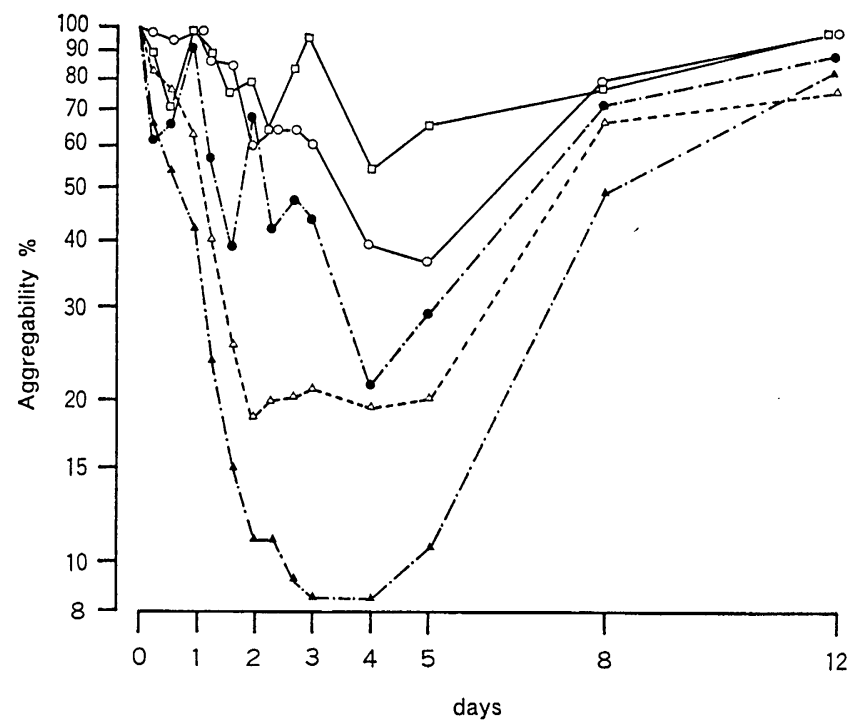

Fig. 4 Time course of platelet aggregability induced by collagen after the repeated oral administration of aspirin and dilazep for 5 days in healthy male volunteers. Each value represents the mean of six volunteers. $\square-\square, 100 \mathrm{mg}$ of dilazep; $\bigcirc-\bigcirc, 10 \mathrm{mg}$ of aspirin; $\Delta-\Delta, 30 \mathrm{mg}$

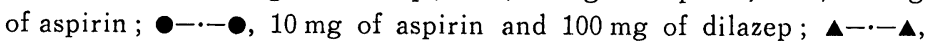
$30 \mathrm{mg}$ of aspirin and $100 \mathrm{mg}$ of dilazep. Medication: t. i. d.

Tab. 3 Time course of plasma levels of $\mathrm{TXB}_{2}$ and 6-keto-PGF $1 \alpha$ before and after the administration of aspirin and dilazep

\begin{tabular}{|c|c|c|c|c|c|c|}
\hline \multicolumn{2}{|c|}{ Dosage } & \multirow{2}{*}{ Before } & \multicolumn{3}{|c|}{ During drug medication } & \multirow{2}{*}{$\begin{array}{l}\text { After } \\
7 \text { days }\end{array}$} \\
\hline $\begin{array}{l}\text { (mg, } 3 \text { times a day } \\
\text { for } 5 \text { days) }\end{array}$ & factors & & $6 \mathrm{hr}$ & $24 \mathrm{hr}$ & 3 days & \\
\hline \multirow[t]{2}{*}{ ASA $10+$ DZP 100} & TXB 2 & 219. $3 \pm 13$ & $125.3 \pm 13^{*}$ & 168. $7 \pm 24$ & $164.7 \pm 22$ & 189. $0 \pm 17$ \\
\hline & 6-Keto-PGF ${ }_{1 \alpha}$ & $33.7 \pm 7.1$ & $38.0 \pm 2.8$ & $44.2 \pm 3.2$ & $42.5 \pm 8.4$ & $38.5 \pm 7.4$ \\
\hline \multirow[t]{2}{*}{ ASA $30+$ DZP 100} & TXB 2 & $235.0 \pm 30$ & $134.0 \pm 15^{*}$ & $154.2 \pm 19^{*}$ & $148.5 \pm 25$ & $182.3 \pm 14$ \\
\hline & 6-Keto-PGF ${ }_{1 \alpha}$ & $31.7 \pm 5.7$ & $40.8 \pm 5.3$ & $41.7 \pm 3.8$ & $39.3 \pm 6.9$ & $46.7 \pm 7.0$ \\
\hline ASA 10 & $\begin{array}{c}\text { TXB 2 } \\
\text { 6-Keto-PGF }{ }_{1 \alpha}\end{array}$ & $\begin{array}{c}179.2 \pm 13 \\
30.7 \pm 3.9\end{array}$ & $\begin{array}{r}122.8 \pm 12 * \\
44.3 \pm 4.2\end{array}$ & $\begin{array}{c}\text { 148. } 2 \pm 9.0 \\
57.5 \pm 10\end{array}$ & $\begin{array}{r}\text { 166. } 4 \pm 19 \\
61.0 \pm 21\end{array}$ & $\begin{array}{l}173.6 \pm 14 \\
32.6 \pm 9.5\end{array}$ \\
\hline \multirow{2}{*}{ ASA 30} & TXB 2 & $205.5 \pm 22$ & $141.2 \pm 20$ & $147.8 \pm 15$ & 153. $8 \pm 21$ & $222.8 \pm 25$ \\
\hline & 6-Keto-PGF $1 \alpha$ & $40.7 \pm 11$ & $65.8 \pm 6.8$ & 49. $3 \pm 3.2$ & $55.0 \pm 13$ & $38.3 \pm 9.0$ \\
\hline \multirow{2}{*}{ DZP 100} & TXB 2 & 198. $0 \pm 24$ & 156. $0 \pm 11$ & 176. $0 \pm 13$ & $161.8 \pm 10$ & $194.5 \pm 35$ \\
\hline & 6-Keto-PGF $1 \alpha$ & $35.3 \pm 5.0$ & $36.4 \pm 6.4$ & $50.0 \pm 9.2$ & $35.2 \pm 12$ & $31.0 \pm 8.0$ \\
\hline
\end{tabular}

Values of $\mathrm{TXB}_{2}(\mathrm{pg} / \mathrm{ml})$ and 6 -keto-PGF $\mathrm{P}_{1 \alpha}(\mathrm{pg} / \mathrm{ml})$ represent mean $\pm \mathrm{SE}(\mathrm{n}=6)$. Significantly different from those before the administration by $t$-test $(*, P<0.05)$.

ability was adopted. Thus a dose-response curve was drawn by plotting the maximal slope $(\% / \mathrm{min})$ of platelet aggregation against the concentration of collagen added to the PRP, and aggregability was calculated from the shift of the curve as a percentage of the pretreatment value. The second fea- ture of the clinicopharmacological test is the use of a crossover study with a definite number of healthy adult male volunteers. The selected volunteers were prohibited from taking non-steroidal anti-inflammatory drugs, especially aspirin, for 2 weeks before and after the experiment. Regretably, a 
complete crossover study was rendered impossible by a number or dropouts. In the single-administration test, volunteer $\mathrm{I}$, who had no problem in Exp. 1, dropped out in Exp. 2, and accordingly volunteers $\mathrm{K}$ and $\mathrm{L}$ had to be newly adopted in Exp. 3 to balance the overall subject numbers in the various groups. In the repeated administration test, there was one dropout during the relatively long (12-day) term of observation (this case is excluded from the results). Therefore, 2 new subjects (volunteers $\mathrm{O}$ and $\mathrm{P}$ ) were added to balance the subject numbers of the various groups. On administration of aspirin alone, dose-dependent anti-platelet actions were detected following the intakes of 30,100 and $300 \mathrm{mg}$; and when aspirin was combined with 100 mg dilazep, the results suggested that the dose of aspirin could be reduced to one-third. Simultaneous measurement of changes in plasma salicylic acid levels and blood dilazep levels revealed that the combination of drugs had no influence on the pharmacokinetics of the individual drugs, suggesting that the potentiation of the anti-platelet action on combined use of the two drugs is due to a synergistic effect between them. In the repeated administration (5-day) test, the results of the single-administration test were taken as reference, and the customary t. i.d. drug administration was adopted. The t.i.d. administration of dilazep $100 \mathrm{mg}$ occasioned a slight decrease in platelet aggregability during the administration period, followed by rapid recovery after cessation. On the t. i.d. administration of aspirin $10 \mathrm{mg}$, aggregability gradually decreased from day 1 , reaching $40 \%$ on day 5 , then recovered almost to the pretreatment value on day 3 after cessation. On combined administration of the two drugs in these doses, aggregability fell to $40 \%$ as early as day 2 after the start of administration. This effect was maintained throughout the administration period, following which aggregability showed a similar recovery to that in the respective drug alone groups. In the aspirin $30 \mathrm{mg}$ t. i. d. administration group, platelet aggregability decreased to $20 \%$ after 2 days but showed no further decrease on continual administration. In the t. i. d. combined administration group of aspirin 30 $\mathrm{mg}$ and dilazep $100 \mathrm{mg}$, a stronger anti-platelet action was demonstrated, and aggregability of about $10 \%$ lasted from days 2 to 5 after the start of administration. The recovery of aggregability after withdrawal of medication was similar in both groups, with aggregability returning to about $60 \%$ of the pretreatment value after 3 days and $80 \%$ after 7 days. Thus, the administration of either aspirin alone or aspirin plus dilazep resulted in a quantitative, dose-dependent decrease in platelet aggregability. On this occasion the plasma levels of $\mathrm{TXB}_{2}$ and 6-keto-PGF $\mathrm{PG}_{1 \alpha}$ (i. e. those produced in the normal circulating blood) were determined rather than their serum levels (i. e. those produced during the process of platelet aggregation). A slight decrease was observed only in $\mathrm{TXB}_{2}$ levels during the administration period, and no change was observed in the level of 6 -keto-PGF ${ }_{1 \alpha}$. This suggests that the aspirin $30 \mathrm{mg}$ t. i.d. oral administration for 5 days does not cause fatal inhibition of systemic arachidonic acid metabolism. ${ }^{20}$ ) In the present study we neither assayed prostaglandins in the urine nor examined $\mathrm{PGI}_{2}$ producibility using the isolated vein. However, in the light of the results reported by P. Patrignani et al. ${ }^{20)}$ S. P. Hanley et al., ${ }^{18,21)}$ G. Masotti et al., ${ }^{22)}$ K. K. Wu et al., ${ }^{23)}$ G. Davi et al., ${ }^{24)}$ and F.E. Preston et al.,5) the dose of aspirin which inhibits only the $\mathrm{TXB}_{2}$ producibility of the platelet without influencing $\mathrm{PGI}_{2}$ production in the vascular wall is $30-40 \mathrm{mg} /$ day. Consequently, the administration of aspirin $10 \mathrm{mg}+$ dilazep 100 $\mathrm{mg}$ (aspirin $30 \mathrm{mg}$, dilazep $300 \mathrm{mg}$ daily) is close to the ideal combination for therapy from the clinicopharmacological standpoint. However, its evaluation as a true antithrombotic therapy may need long-term observation in various thrombotic diseases.

\section{References}

1) Fields, W.S., Lemak, N. A., Frankowski, R. F. et al. : Controlled trial of aspirin in cerebral ischemia. Stroke, 8 : 301-316 (1977).

2) Canadian Cooperative Study Group : A randomized trial of aspirin and sulfinpyrazone in threatened stroke. New Engl. J. Med., 299 : 5359 (1978).

3) Persantin-Aspirin Reinfarction Study Research Group : Persantin and aspirin in coronary heart disease. Circulation, 62: 449-461 (1980).

4) Vabe, J. R. : Inhibition of prostaglandin synthesis as a mechanism of action for aspirin-like drugs. Nature New Biol., 231: 232 (1971).

5) Preston, F. E., Greaves, M., Jackson, C. A. et al. : Low-dose aspirin inhibits platelet and venous cyclo-oxygenase in man. Thromb. Res., 27 : 477-484 (1982). 
6) Basista, M., Dobranowski, J. and Gryglewski, R. J.: Prostacyclin and thromboxane generating systems in rabbits pretreated with aspirin. Pharmacol. Res. Commun., 10: 759-763 (1978).

7) Louie, S. and Gurewich, V.: The antithrombotic effect of aspirin and dipyridamole in relation to prostaglandin synthesis. Thromb. Res., 30: 323-335 (1983).

8) Hanley, S. P., Bevan, J., Cockbill, S. R. et al. : A regimen for low-dose aspirin. Br. Med. J., 285 : 1299-1302 (1982).

9) Sano, N.: Enhancement of coronary vasodilating action of adenosine by dilazep and dipyridamole in the dog. Jpn. J. Pharmacol., 24: 471-478 (1974).

10) Buyniski, P. J., Losada, M., Bierwagen, E. M. et al. : Cerebral and coronary vascular effects of a symmetrical N., $\mathrm{N}^{\prime}$-disubstituted hexahydrodiazepine. J. Pharmacol. Exp. Ther., 181: 522528 (1972).

11) Katsunuma, H., Kiyokawa, M., Iwamoto, T. et al.: Effects of dilazep on hemoglobin-oxygen affinity in patients with cerebrovascular disease and its clinical aspects. Kiso to Rinsho, 15 : 808-819 (1981) (in Japanese).

12) Nakajima, K., Yamamoto, S., Tsukamoto, M. et al. : Effects of dilazep on fibrinolytic system in animals. 1. Enhancement of fibrinolytic activity by administered dilazep in ex vivo experiment. J. Pharm. Dyn., 5: 356-362 (1982).

13) Nakajima, K.: Pharmacological observations of plasminogen activator release caused by vasoactive agents in isolated perfused pig ears. Thromb. Res., 29 : 163-174 (1983).

14) Yasunaga, K., Kanzaki, M. and Kimura, M. : Inhibition of platelet aggregation by dilazep dihydrochloride. Jpn. Arch. Int. Med., 27 : 99-107 (1980) (in Japanese).

15) Sumiyoshi, A. and Hayashi, T.: The inhibitory effect of dilazep on in vivo accumulation of platelets onto the damaged aorta in rabbits. Thromb. Res., 29: 37-42 (1983).
16) Valori, V. M., Leone, G. and Bizzi, B. : A comparative study on the effect of dilazep and dipyridamole on some platelet function. ArzneimForsch., 32: 403-405 (1982).

17) Yamamoto, S., Nakajima, K., Nagakura, M. et al.: Platelet aggregability and aortic prostacyclin production after the combined treatment with dilazep and aspirin in rat, rabbits and healthy volunteers. Blood \& Vessel, 15: 644651 (1984). (in Japanese).

18) Born, G. V.R. and Cross, M. J.: The aggregation of blood platelets. J. Physiol., 168: 178-195 (1963).

19) Rajah, S. M., Penny, A.F., Crow, M. J. et al. : The interaction of varying doses of dipyridamole and acetly salicylic acid on the inhibition of platelet functions and their effect on bleeding time. Br. J. Clin. Pharmacol., 8: 438-489 (1979).

20) Patrignani, P., Filabozzi, P. and Patrono, S. : Selective cumulative inhibition of platelet thromboxane production by low-dose aspirin in healthy subjects. J. Clin. Invest., 69: 1366-1372 (1982).

21) Hanley, S. P., Bevan, J., Cockbill, S. R. et al. : Differential inhibition by low-dose aspirin of human venous prostacyclin synthesis and plate. let thromboxane synthesis. Lancet, May 2, 969971 (1981).

22) Masotti, G., Galanti, G., Poggesi, L. et al.: Differential inhibition of prostacyclin production and platelet aggregation by aspirin. Lancet, December 8, 1213-1216 (1979).

23) Wu, K.K., Chem, Y.C., Fordham, E. et al. : Differential effects or two doses of aspirin on platelet-vessel wall interaction in vivo. J. Clin. Invest., 68: 382-387 (1981).

24) Davi, G., Custro, N., Novo, S. et al. : The effect of two low doses of aspirin on whole blood thromboxane and prostacyclin generation in healthy subjects. Thromb. Haemost., 50: 669670 (1983). 